\title{
LX. The ignition of gases by hot wires
}

\author{
W.M. Thornton D.Sc. D.Eng.
}

To cite this article: W.M. Thornton D.Sc. D.Eng. (1919) LX. The ignition of gases by hot wires, Philosophical Magazine Series 6, 38:227, 613-633, DOI: 10.1080/14786441108635989

To link to this article: http://dx.doi.org/10.1080/14786441108635989

册 Published online: 08 Apr 2009.

Submit your article to this journal $\pi$

Џ Article views: 2

Q View related articles $\asymp$

4 Citing articles: 2 View citing articles 


\section{$\left[\begin{array}{ll}613 & ]\end{array}\right.$}

LX. The Ignition of Gases by Hot Wires. By W. M. Thornton, D.Se., D.Fing., Professor of Electrical Engineering in Armstrong College, Newcastle-upon-Tyne *.

1. Introduction.

2. Experimental Method.

3. Influence of Metal and Diameter of Wire.

4. Methane.

5. Heat of Combustion of Gas.

6. Heat generated by Current.

7. Convection.

8. Surface Combustion.
9. Temperature of Wires at which Irnition begins.

10. Nature and Prupurtion of Combustible Gas in Mixtures.

11. Gas Pressure.

12. Flectric and Magnetic Fields.

13. Application of Results.

14. Summary.

\section{Introduction.}

A RED-HOT metal in contact with a gas loses energy as A heat and by the discharge of ions or electrons. Radiation has little if any effect on gaseous combination except in well-known mixtures that are sensitive to light.

When the source is a hot wire conduction and convection effects are inseparable; the effect of ionic discharge has not hitherto been examined. Paterson and Campbell have recently given evidence $t$ in support of the view that ionization is the chief agent in ignition by spark discharge, and have confirmed the existence of stepped ignition, escentially a selective phenomenon. All such singular time effects are necessarily absent from hot-wire ignition. By their elimination tha problem of innition is simplified to the question of how far gaseous combination can be started by a hot wire at temperatures below those at which gases combine when heated by external action, such as passage tbrough hot tubes or sudden compression, and whether it is a purely thermal effect.

Previous work on hot wire ignition, done to determine safe limits to the use of electricity in coal mining, deals only with methane. W'̈̈llner and Lehmann's investigation for the Prussian Fire Damp Commission of 1881 was the first systematic work on the subject $\ddagger ; \S 57$ deals with ignition

* Communicated by the Author.

† "Some Characteristies of the Spark Discharge, and its Effect in Igniting Explosive Mixtures," by Clifford C. Paterson, M.I.C.E., M.I.E.E., and Norman Campbell, Sc.D. Proc. Physical Soc. London, vol. xxxi. Part IV. June 15th, 1919, pp. 168-228.

\pm Report of the Prussian Fire-1)amp Commission (1884). Trans. for the $I_{1}$ stitution of Mining Engineers, by Prof. P. P. Bedson.

Phil. Mag. S. 6. Vol. 38. No. 227. Nov. 1919. 2 U 
of firedamp by heated wires. The researches of Hauser* in Spain, and and of Couriot and Meunier ${ }^{\dagger}$ in France, deal with the possibility of igniting methane by hot wires, platinum in particular. Mallard and Le Chatelier examined ignition of tiredamp by the heated gauze of safety-lamps. More recently the properties of hot tungsten filaments have been investigated at the Bureau of Mines in Washington, by breaking lamps in an inflammable mixture.

The influence of hot surfaces on combustion is fully discussed in $\S$ VI. of Prof. W. A. Bone's Report on Gaseous Combustion to the Sheffield merting of the British Association (1910). The present paper deals with the special problem of ignition by hot wires such as may occur in coal mines, battery rooms of submarines, or in manufacturing processes where combustible gas is set free, but the bearing of the results on the more general question of surface combustion has been considered throughout.

\section{Experimental Method.}

In work of this kind it is desirable to use as large a volume as possible to ensure that the explosion wave is fully established. On the other hand, convection currents are so marked at high temperatures that the use of too large a vessel is equivalent to enclosing the wire in a tube and passing a strady current of gas over it. It is known that a current of gas is favourable to ignition by hot platinum wires in tubes.

When many trials are to be made in quick succession it is found convenient to use a cylindrical glass vessel of 50 cubic centimetres volume, having short opposite branches. Through a stopper in one of these pass two copper rods $2 \mathrm{~mm}$. diameter, to the ends of which the wires to be tested are soldered, either straight as at $b$, fig. 1, or forming an arch as at $a$. Through the opposite branch plates or tubes were ltd by which any desired electrostatic field could be maintained on the wire. When these are fixed in position the vessel is exhausted, a current from a low voltage battery passed for a few seconds to drive off organic contamination, and the inflammable mixture admitted, the wire then being cold. The electric

* Collected in Leçons sur le Grisou, E. Hauser, Madrid, 1908. See Abs. by L. Denoël, Annales des Mines de Belgique, t. xii. p. 1088 (1907).

$\dagger$ Couriot et J. Meunier, "Sur l'inflammation du Grisou par les Conducteurs électriques incandescents." Ann. d. Min. d. Belgique, 1908, p. 87. 
current is then made and raised quickly, a voltmeter connected across the wire being constantly observed, so that change of resistance can be measured and the temperature estimated. It is found that there is for every diameter and

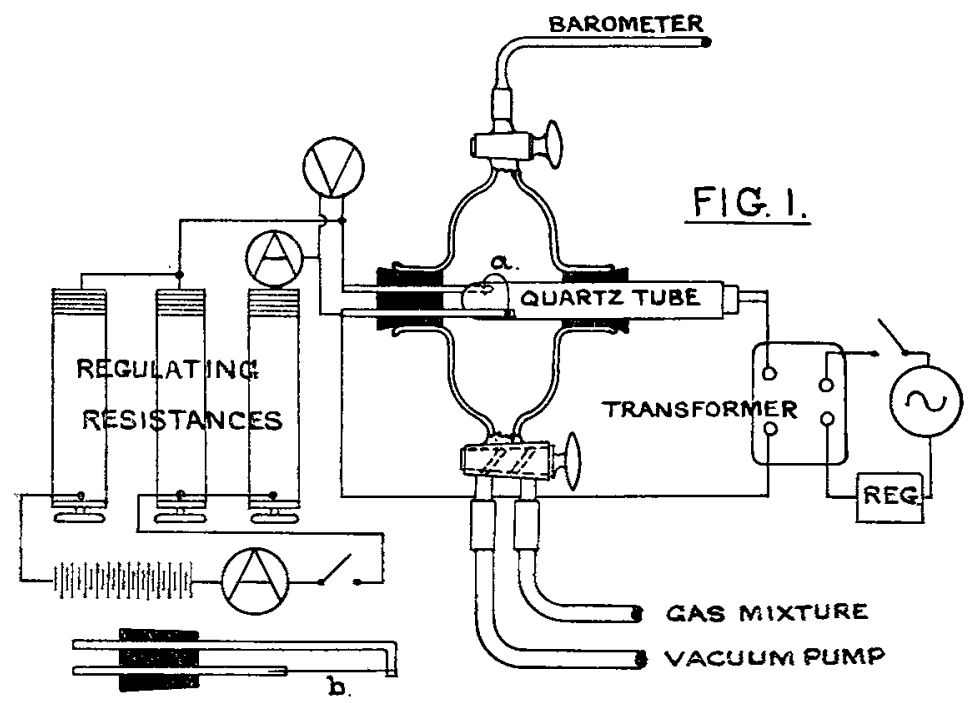

metal a particular current which when made suddenly, not approached slowly, just causes ignition. This current is very sharply defined and is not quite the same for old and new wires: the former ignite gas rather more easily than fresh wires, though the variation is at most a few per cent. It does not seem to depend upon the mechanical state of the wire so long as its diameter does not change with use, as in the case of tungsten which undergoes a permanent extension of as much as 20 per cent. after heating, contracts in diameter, and becomes brittle.

\section{Influence of Metal and Diameter of Wire.}

Wires of pure platinum, nickel, iron, tungsten, molybdenum, gold, and silver were obtained in three sizes, about $0.1,0.2$, and 0.3 millimetre diameter, and formed into lengths or loops 3 centimetres long. In these sizes copper melts too readily to be used. The exact length of wire did not matter so long as 1 to $1 \frac{1}{2}$ centimetres of it glowed brightly. The same results were obtained with straight as with curved wires. The gases were hydrogen, methane, ethane, pentane, methyl and ethyl alcohol, ethylene, ethyl $2 \mathrm{U} 2$ 
616

Prof. W. M. Thornton on the

ether, benzene, carbon monoxide, coal gas, and petrol vapour.

The methane was kindly sent highly purified by Dr. R. V.

Wheeler. Ethane was prepared by the copper-zinc couple from ethyl iodide. In this and the other gases the usual

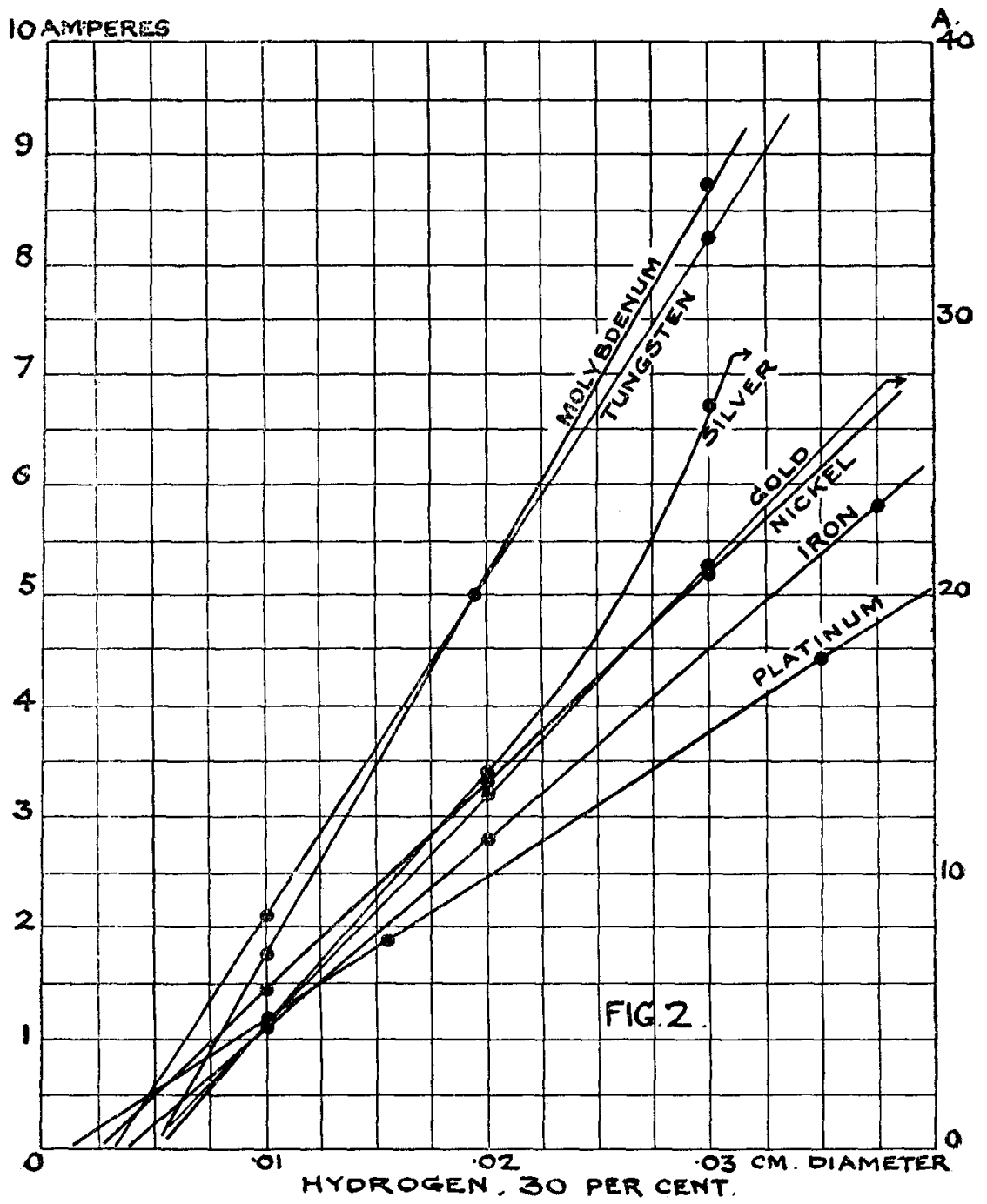

means of purification were used short of liquefaction, but, as will be shown, the results in different gases are so much alike that, except for special purposes, high purification is unnecessary.

The results of the trials in hydrogen are shown in fig. 2, 
the mixture being 30 per cent. of gas in air. The observations are represented by straight lines which cut the horizontal axis at points between $\cdot 03$ and $\cdot 05$ millimetre diameter. Ignition is abmormally difficult with thick silver wires. The current $i=a+b d$, where $a$ is negative and $l$ increases with the conductivity of the wire. The coefficient $a$ is the current which would give heat to the wire equivalent to that caused by surface combustion in wires of negligible diameter. The coefficient $b=\frac{\delta i}{\delta d}$, the slope of the lines, is closely proportional to the conductivity as shown in lable I., so that $i=a+k \sigma d$, where $k$ has a mean value of $1 \cdot 67 \cdot 10^{-3}$ in hydrogen. $a$ is also proportional to $\sigma$, having a mean value $1 \cdot 16 \cdot 10^{-3}$. $k$ does not vary more than the wires may do from their mean value, though hydrogen is undoubtedly ignited by platinum more readily than by other metals.

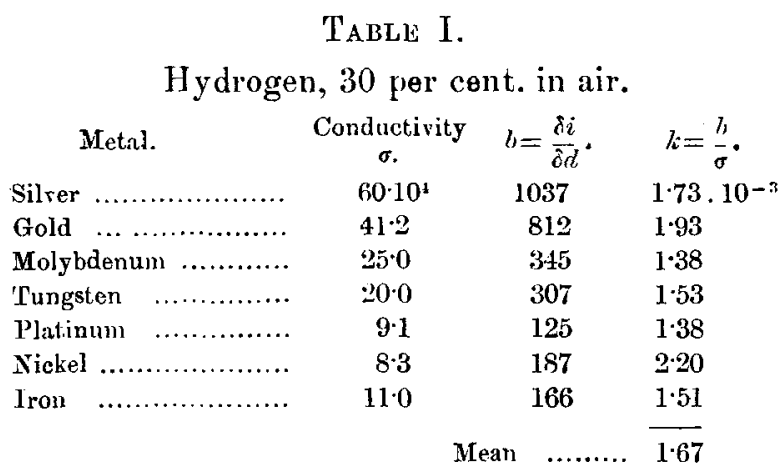

From an extended series of measurements, the results of which are collected in Tables II. and III., this type of relation holds in all gases.

TABLE II.

Platinum Wires (from three diameters).

$$
\text { Gas. }
$$

Hydrogen

Carbon Monoxide

Methyl Alcohol

Ethyl Alcobol...

Ethylene

Ethyl Ether

Benzeve

Pentane
Per cent. Calorific
in Air.

$30 \quad 58$ 1.c. $\quad 125$

$\begin{array}{lll}33 & 68 & 177\end{array}$

$13.0 \quad 182 \quad 202$

$3.5 \quad 340 \quad 208$

$7 \cdot 0 \quad 333 \quad 197$

$355 \quad 660 \quad 208$

$45 \quad 799 \quad 205$

$3.5 \quad 850 \quad 204$ 
TABLE III.

Tungsten Wires.

\begin{tabular}{|c|c|c|c|}
\hline Gas. & $\begin{array}{l}\text { Per cent. } \\
\text { in Air. }\end{array}$ & $\begin{array}{c}\text { Calorific } \\
\text { Value. }\end{array}$ & $b$. \\
\hline Hyclrogen & 30 & 58 l.c. & $307 *$ \\
\hline Carbon Monoxide ......... & 33 & 68 & 340 \\
\hline 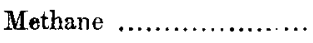 & 10 & 212 & 340 \\
\hline Coal Gas... & 15 & c. 120 & 330 \\
\hline
\end{tabular}

* With molybdenum wires $b$ was 345 .

\section{Methane.}

There is very great difficulty in igniting methane by any wire whose melting-point is below about $1800^{\circ} \mathrm{C}$. It is practically impossible to do so with platinum except in a stream of gas. This confirms the observations of Wüllner and Lehmann and Couriot and Meunier. When a vessel is used of so large a volume that fresh gas is swept over the wire continuously by convective movement ignition can in certain cases occur, but in a vessel of the volume and shape used here it was not found possible to ignite metbane, in any proportion of mixture, by platinum wires. This might well have been the result of complete burning out of the connbustible gas or the formation of an inert residue. In order to test this a sparking plug was fitted in one of the cross arms of the explosion vessel. After the platinum wires had become white-hot, melted and fused in the mixture without igniting it, a spark was passed at the plug. In every case explosion followed.

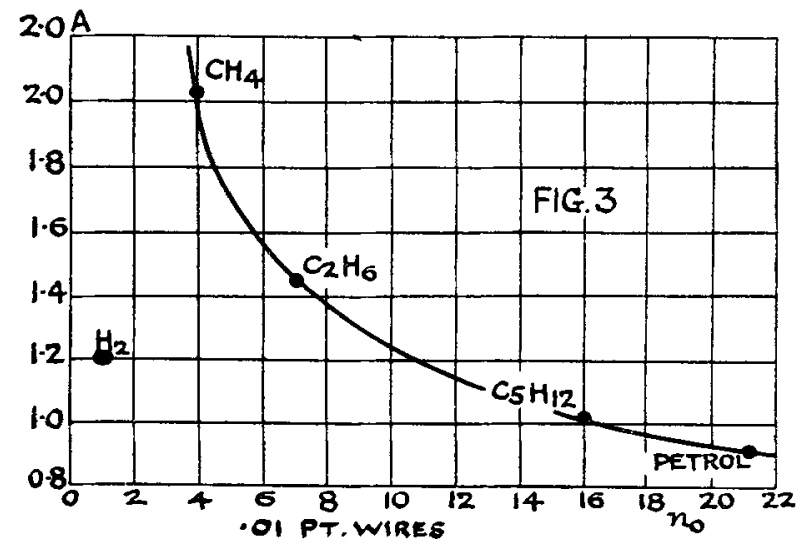

An estimate of the current which would ignite methane by 0.1 millimetre platinum wire, if this did not melt, can be made from results with ethane, pentane, and petrol given 
later. A curve, fig. 3, through these cuts the position of methane at 2 to $2 \cdot 1$ amperes. Platinum wires $01 \mathrm{~cm}$. diameter soften and break at about $2 \cdot 0$ amperes. It is just possible, therefore, to ignite methane in a 10 per cent. inixture by wires on the point of melting.

This difference between hydrogen and the other members of the paraffin series is peculiar to platinum-wire ignition. With tungsten wires there is no difference between the igniting currents of hydrogen, methane, carbon monoxide, or coal gas. The ignition of hydrogen and the higher paraftins begins at temperatures well below redness. Ethane and methane require high temperatures. Tungsten is always at red-heat before ignition begins.

\section{Influence of Heat of Combustion of the Gas.}

It is evident from the figures of Tables II. and III., that the caloritic value of the combustible gas does not perceptibly modify the conditions of iguition, nor is it a question of adjustment of percentage so that the calorific value of unit volume remains constant, tor ethyl alcohol, ether, and pentane were used in the same strength of mixture, and have the same slope of line though their calorific values are widely different. The curve of fig. 3 would at first sight suggest that igniting current is inversely proportional to calorific value. It follows closely the relation $(\mathrm{I}-\cdot 69) n_{0}=5 \cdot 25$, where $n_{0}$ is the number of oxygen atoms required for complete buruing of one molecule of the combustible gas. Calorific value is proportional to $n_{0}$, so that the curve might equally well be drawn on a heat base. The absence of any such relation when tungsten wires are nsed would, however, seem to rule the latter out, so that the more difficult ignition of the lighter paraffins by platinum wires may arise rather from difficulty of their "sorption," and the emission by platinum at low temperatures of ions derived from the paraffin molecule. The absorption and adsorption of the paraffins by platinum should be further investigated from the point of view of surface combustion.

\section{Influence of Heat generated by the Current.}

Ignition is a matter of intensity of action rather than of dissipation of a certain quantity of heat. The heat generated per second in unit length of a wire of diameter $d$ and conductivity $\sigma$ is $\mathrm{H}=4 i^{2} / \pi d^{2} \sigma$. For the same gas mixture

$$
b=\frac{\delta i}{\delta d}=\sqrt{\pi \mathrm{H} \sigma} / 2,
$$

a constant for any particular metal provided that ignition 
depends only upon H. From Table I., and still better from a graph of the figures given there, it is seen that $k$, the ratio of $b$ to $\sigma$, is as a first approximation constant.

Thus

$$
k \sigma=\frac{\sqrt{\pi H \sigma}}{2}, \quad \sigma=\frac{\pi H}{4 k^{2}}, \quad \text { and } \quad l=\frac{\pi H}{4 k} .
$$

Since $\ell$, Table II., is found experimentally to be a constant ratio for any given wire, $\mathrm{H}$ is constant. Ignition of all gases but hydrogen and carbon monoxide occurs at the same rate of generation of heat in unit length of wire. This clearly points to ignition starting by thermionic emission under the same electron pressure in each case.

\section{Influence of Convection.}

Since a steady state is reached, at least in the smaller wires, at the moment of ignition, it may be concluded that the heat generated by the current which first starts surface combustion is removed in a manner that does not depend upon the diameter or surface of the wire. In support of this Kennelly's observations may be quoted, that the cooling of a wire bv convection is approximately the same for unit length of all small diameters.

\section{Surface Combustion.}

In a wire heated both by current and surface combustion there is a temperature of equilibrium between the heat dissipated by radiation and convection and that generated.

Let $\mathrm{H}_{c}$ be the heat of combustion of one gramme of gas, not the mixture, and $m$ the mass of gas burnt per second. The heat removed by convection is proportional to the first power of the temperature *. So that in calories

$$
m \mathrm{H}_{c}+\cdot 24 r i^{2}=\mathrm{K}\left(\theta^{4}-\theta_{0}^{4}\right)+\cdot 24(\cdot 0004+\cdot 0064 d)\left(\theta-\theta_{0}\right) .
$$

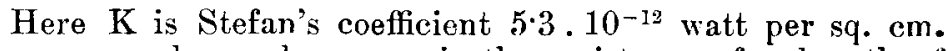
per second per degree, $r$ is the resistance of $a$ length of wire of unit area.

In the case of hydrogen ignited by $0.1 \mathrm{~mm}$. platinum the length of wire with unit surface is 32 centimetres, giving $4.4 \mathrm{ohms}$ resistance. The igniting current of hydrogen is 1.2 amperes, for which $r i^{2}=6.33$ watts. The mass of hydrogen which must be burnt per second to give equilibrium

* "The Conrection of Heat from Small Copper Wires." By A. E. Kennelly, C. A. Wright, and J. S. van Bylevelt. Trans. Amer. Inst. Elec. Eng. 1909, p. 719. 
at say $1300^{\circ} \mathrm{C}$, absolute, which is about the observed brightness, is, taking the vessel at $27^{\circ} \mathrm{C}$., given by

$$
m \mathrm{H}_{c}+\cdot 24 i^{2}=\mathrm{K}\left(\theta^{4}-\theta_{0}^{4}\right)+\cdot 24(\cdot 0004+\cdot 0064 d)\left(\theta-\theta_{0}\right) .
$$

$\mathbf{H}_{c}$ is here 29,000 calories, $d=\cdot 01$ centimetre.

From which

$$
\begin{aligned}
m & =1 \cdot 255 \cdot 10^{-4}+3 \cdot 82 \cdot 10^{-6}-1 \cdot 18 \cdot 10^{-7}-5 \cdot 23 \cdot 10^{-5} \\
& =\cdot 0000524 \text { gram per square centimetre per second } \\
& =\frac{1 \cdot 63}{10^{6}} \text { gram per linear centimetre per second. }
\end{aligned}
$$

The explosion vessel filled with a 30 per cent. mixture contains $15 \mathrm{c} . \mathrm{cm}$. of hydrogen or $\cdot 00135 \mathrm{gram}$. To burn this by a $3 \mathrm{~cm}$. Iength of wire from 30 per cent. to 10 per cent. of mixlure takes $00089 / 4 \cdot 89.10^{6}$ seconds, that is 182 seconds. The surface combustion glow should therefore last three minutes to complete blackness again, and this is much the time observed though the final extinction is not well marked.

In certain cases of rich mixtures the electric heat may be cut off and the wire continues to glow by surface combustion alone. The duration of the glow is then less than when the wire carries a current.

\section{Temperature of Wires at Ignition.}

The least igniting current is that which starts gaseous combination at such a rate that explosion follows. In every case there is surface combustion which may proceed at a steady rate without giving rise to explosion though the wire is glowing brightly. The phenomena before the wire glows in an explosive mixture are extremely interesting. The wire is in almost every case darker in appearance than at the same electric current, in air alone. In hydrogen and benzene particularly, the effect is marked. If before explosion the $2 \mathrm{~mm}$. tap at the top of the explosion vessel is opened so that air can be drawn in after explosion by contraction of the products, the wire glows more brightly, and continuously, after explosion than before, the current remaining constant.

A sensitive voltmeter connected across the filament shows that as the current is increased the resistance begins to rise, slowly at first and then with a rush, the current meanwhile changing very litıle, from a point at which the wire is apparently cold. At ignition the wire appears incandescent, yet the readings of the voltmeter indicate a temperature 
much below that of the burning gas. For example, it has been shown that a platinum wire $\cdot 01 \mathrm{~cm}$. diameter, heated by a current of $1 \cdot 2$ amperes in a 30 per cent. mixture of hydrogen and air, ignited the gas. The same wire was just visibly red at 1.44 amperes in air. At 1.2 amperes the voltage drop across the filament was 0.64 volt, which rose quickly to 82 , at which point it paused for a moment and the gas exploded. The resistance of the wire therefore increased from $0.53 \mathrm{ohm}$ to $0.68 \mathrm{ohm}$, while the current remained constant on account of the relatively large external resistance in the circuit. The temperature at 12 amperes was found to be between $120^{\circ} \mathrm{C}$. and $140^{\circ} \mathrm{C}$., the wire was therefore quite dark. The rise of temperature corresponding to a 28 per cent. change of resistance is $73^{\circ} \mathrm{C}$. I gnition therefore brgan when the temperature of the wire did not exceed $213^{\circ} \mathrm{C}$.

In carbon monoxide the resistance changed by 46 per cent. with $1 \cdot 12$ amperes steady in the wire, showing a rise of $120^{\circ} \mathrm{C}$. and a final temperature of about $240^{\circ} \mathrm{C}$. In coal gas the change was 23 per cent., giving a final temperature of ignition of $200^{\circ} \mathrm{C}$. These temperatures are of the same order as those given by Bone as the starting point of surface combustion.

Taking now these latter wires and heatiug them with air alone in the explosion vessel, it required a change of 37 per cent. in their resistance as measured to raise them to just visible redness in the dark. Yet at the moment of explosion at the end of the above recorded rise of voltage, the wire had the appearance of glowing brightly except for a millimetre or two at each end where the leading-in rods cooled it. The length heated to redness was never less than half the length of the wire. Taking the worst case of a wire in which the curve of temperature is a parabola falling to zero at each end, the mean temperature is $\frac{2}{3}$ of the maximum, and in any other ease it is $\frac{1}{3}(2+r)$ of it, where $r$ is the ratio of the length of the middle uniform part to the whole. In thin wires $r$ is very nearly unity. The temperature can then be determined from the resistance of the wire with fair accuracy at moderate temperatures, and if necessary Callendar's correction can be applied.

In no case does the resistance of the bright platinum wire indicate temperatures approaching those of Dixon and Coward * for ignition of gaseous mixtures heated by external action. Their mean value for hydrogen in air was

* H. B. Dixon and H. F. Coward, Chem. Soc. Jour. xcv. pp. 514-543 (March 1909). 
$585^{\circ} \mathrm{C}$.. of carbon monoxide $651^{\circ}$, of methane about $700^{\circ}$, and these were practically the same in air as in oxygen.

Observing the wire through a microscope in a combustible mixture the surface appears quite dark until a certain value of the current is reached when it glows suddenly, in some cases to an apparent white heat. There is no corona effect or glow in the gas itself. The whole action appears to be inside the surface of the wire. When there is no combustible gas present the wire when visibly hot merely glows steadily at a temperature reached as slowly is the current is raised.

When there is surface combustion the outside layer is undoubtedly radiating freely, yet the resistance indicates a mean temperature much lower than the optical temperature. The surface of the platinum wire is polished and a reflector. It is conceivable that the heat generated by surface combustion never penetrates the metal but is reflected from the surface as soon as made. If all the energy of combustion were set free as radiation, the gas, through which radiation passes withont effect, would never be ignited, and this wonld account for the fact of wires glowing white hot by surface combustion not igniting explosive mixtures surrounding them. The rate of combination is raised by increasing the current, and as the action becomes more intense the heat set free cannot all be got rid of as radiation, the true temperature of the surface begins to rise rapidly and explosion follows.

The process of ignition by hot platinum wires would then appear to be that at a temperature about $200^{\circ}$ ('. an active discharge begins to take place from the surface which when sufficiently intense starts gaseous combination spreading into surface combustion over the exposed area. This combustion depends for its maintenance upon a continued supply of heat from within or of ions passing through the surface double layer, for on stopping the current in most cases it ceases. The rate of surface combustion depends to some extent upon the true temperature of the surface metal. When this exceeds a value which possibly is that at which free gases combine, as distinct from surface combustion, the mixture explodes. Until this value is reached it is possible to have surface temperatures, certainly in appearance as high as the melting-point of iron, derived from the sustained combination of the gas in ranewed contact with the wire, the energy of which is dissipated as radiation and does not ignite the gas.

Coating platinum wires with aluminium phosphate, which gives a vigorous emission of positive ions at low temperatures, suppresses surface combustion and retards ignition of 
hydrogen until the wires are red-hot, the current then being nearly 2 amperes as against $1 \cdot 2$ when uncoated. After several explosions the salt is driven off, the metal surface is seen, though it is not so bright, and the igniting current returns to $1 \cdot 2$ amperes. Ignition does not depend therefore upon the emission of positive ions alone, but upon some action upon the combustible molecule by contact with and possible penetration of the incandescent layer. This supports the suggestion of Sir J. J. Thomson that " the action of surfaces might ultimately be found to depend on the fact that they formed a support for layers of electrified gas in which chemical changes proceeded with high velocity." (Brit. Assoc. Discussion loc. cit.)

Hauser holds the view that explosion of mixtures of methane by hot platinum is made by contact with gas burning at the surface. Couriot and Meunier, on the other hand, regard ignition as entirely due to the heat from the wire.

The temperature of ignition is certainly not the apparent temperature of surface combustion, nor is it that of the wire that starts it, though hoth take part in the action.

\section{Influence of the Nature and Proportion of Combustible Gas in the Miatures.}

Comparison of the values of the coefficient $b$ in Tables II. and III. leads to the conclusion that the chemical nature of the combustible molecule has little influence on hot-wire ignition by tungsten or molybdenum, and that with platinum $b$ approaches a steady value when the molecular weight is about 60 . That is, hydrogen atoms cease to have any distinctive influence on plitinum ignition of hydrocarbons above this point.

The proportion of combustible gas has in general little effect on the igniting currents ; those of coal gas, fig. 4, are sensibly the same over the whole range of ignition.

\section{Table IV.}

Methane. Tungsten Wires.

$\begin{array}{cc}\text { Percentage of } & \text { Igniting } \\ \text { Gas in Air. } & \text { Current. } \\ 6 \cdot 7 & 5 \cdot 05 \text { amperes. } \\ 8 \cdot 0 & 5 \cdot 20 \\ 10 \cdot 0 & 5 \cdot 25 \\ 12 \cdot 0 & 5 \cdot 30 \\ 13 \cdot 5 & 5 \cdot 30\end{array}$


In methane, Table IV., the current is also the same in all mixtures, but here $\cdot 2 \mathrm{~mm}$. tungsten wires were used, platinum melting.

$10 \mathrm{~A}$.

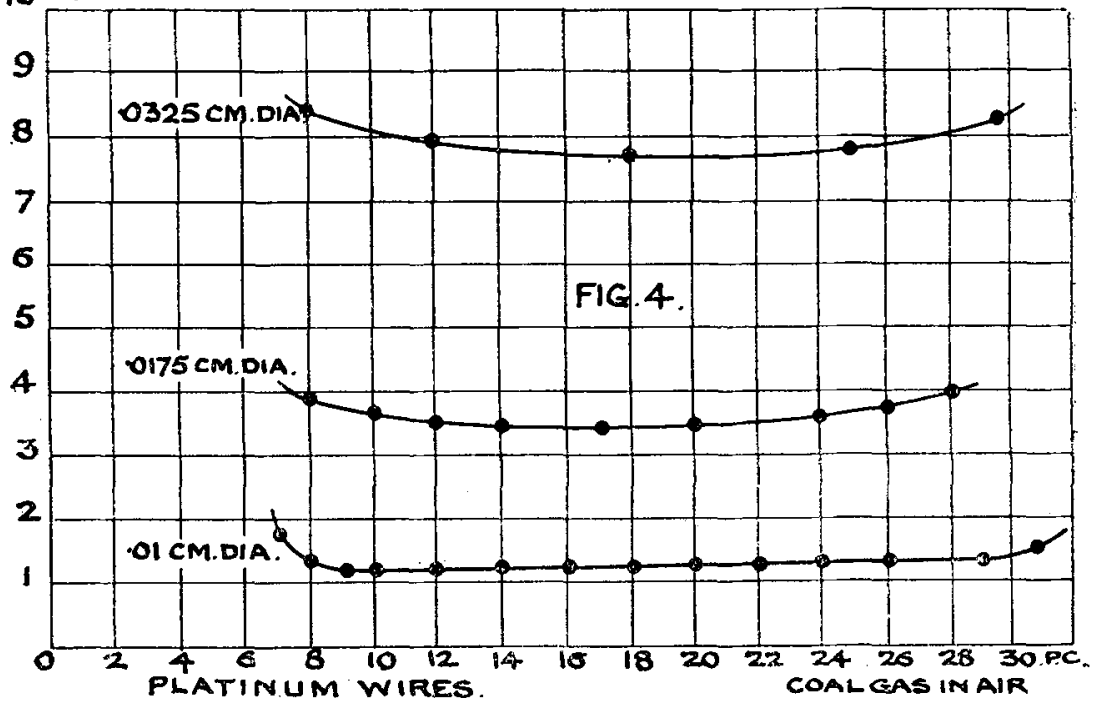

This current, $5 \cdot 25$ amperes, is the same as in hydrogen, fig. 2, and in carbon monoxide. The curves of hydrogen, ethylene, and coal gas, drawn to the same scale in fig. 5, have the same small slope of base. Ignition fails with surprising suddenness at the lower limit. It may be noted that the slope of the base is uniform; it is therefore not due to any change in the influence of the heating effect of the wire, which would vary as the square of the current. Ignition increases in difficulty as the oxygen percentage diminishess and the point of perfect combustion is passed through without notice. Excess of oxygen is here farourable to ignition. In carbon monoxide, however, the igniting current has at quite constant value from 30 to 55 per cent., as in methane.

Hydrogen, methane, and carbon monoxide are the chief constituents of coal gas. Since each of these has the sume igniting current it was to be expected that coal gas would not be different. Its igniting current was found on trial to be $5 \cdot 3$ amperes.

The ignition of ethane resembles that of methane in not being affected by change of composition, and having sharp limits. It took 1.44 amperes from 3 to 8.5 per cent. with a $1 \mathrm{~mm}$. platinum wire which was then red before surface 
combustion began. Pentane, fig. 6 , differed somewbat from ethane in the rounded lower limit. The point from which
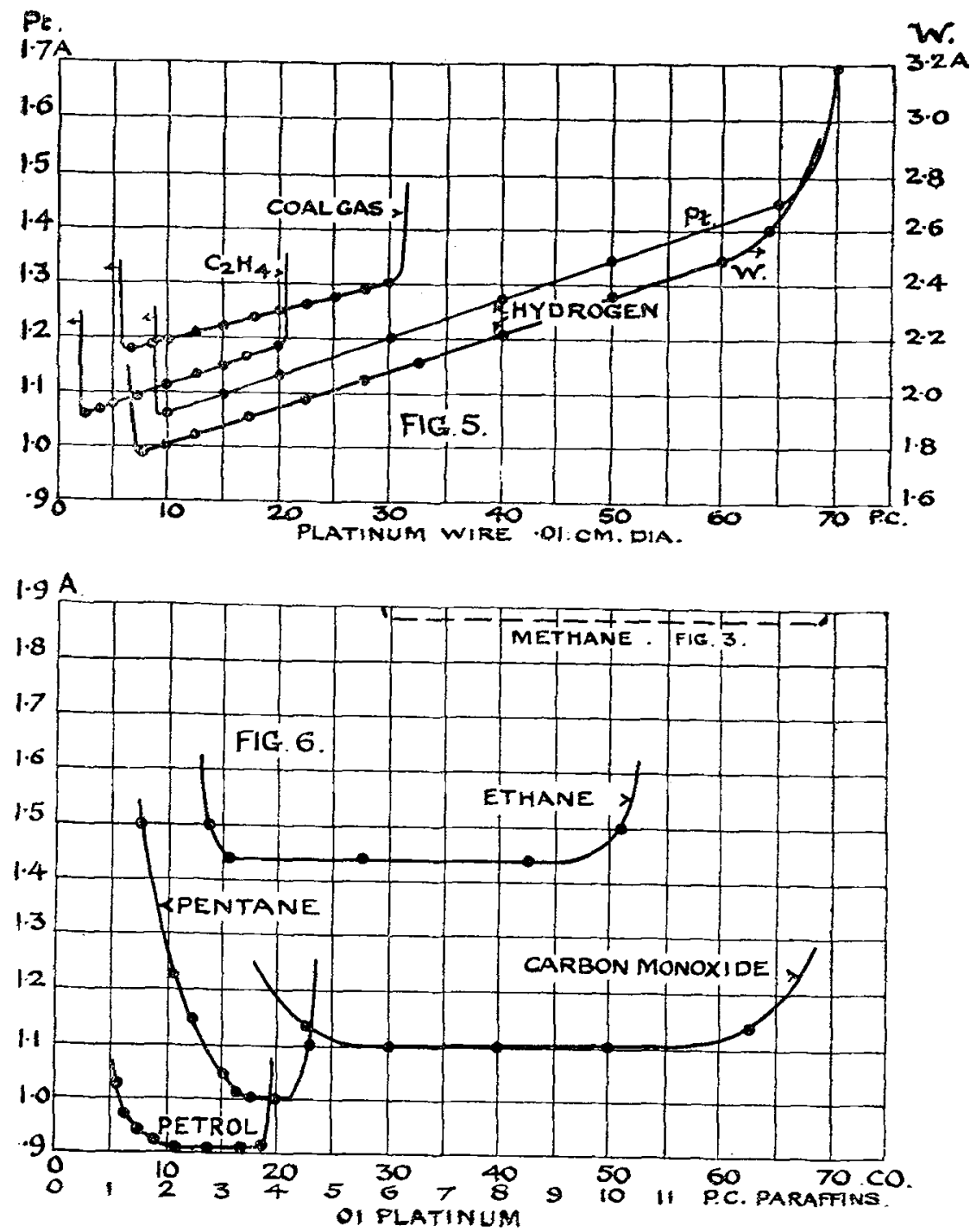

the rise starts corresponds to combustion to $\mathrm{CO}$, not to $\mathrm{CO}_{2}$. Petrot also has a flat base and a slow approach to the lower limit. 'The last two are more sensitive to hot-wire ignition than hydrogen. 
Methyl and Ethyl alcohol, fig. 7, take the same mean current, 1.2 amperes, but the former is more difficult to

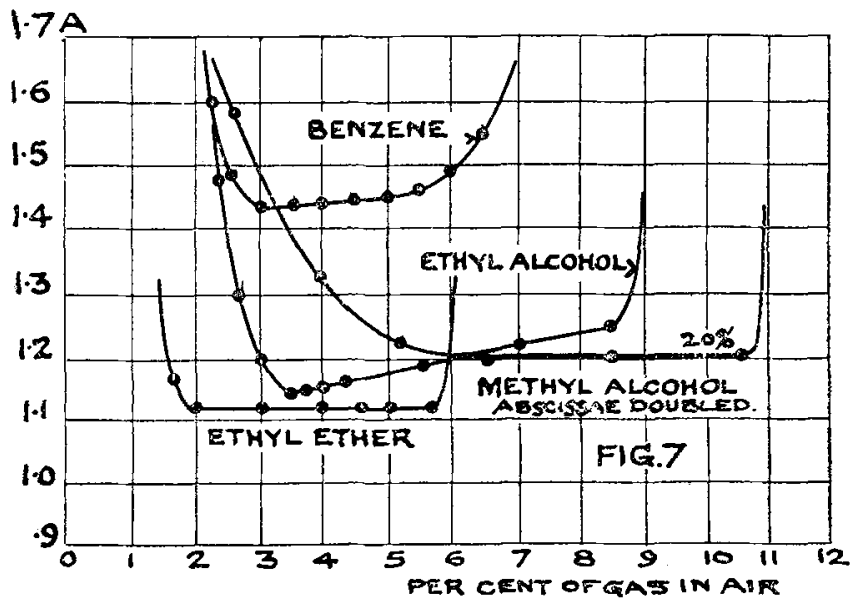

ignite in the weaker mixtures, the curve rising from $12 \cdot 0$ per cent., the mixture for perfect combustion. The base of methyl alcohol is flat, resembling methane, that of ethyl alcohol slopes rather more than the curves of fig. 5 .

Ethyl ether is slightly more inflammable, with sharp limits and a flat base. Benzene compares with ethane in maguitude of igniting current and has a practically flat base.

There is therefore strong evidence that $i_{m}$ nition of most gases by hot wires is within a small range of current independent of the proportion of combustible gas present. This had been observed by Couriot and Meunier in the case of methane, and is characteristic of certain forms of spark ignition, for example of hydrogen and carbon monoxide by break sparks*, methane by impulsive discharge $\dagger$. All cases of stepped ignition by sparks are examples of the same phenomenon + , the difficalty of ignition changing suddenly at each step, where the proportion of oxygen to combustible gas passes through integral values, or as in Paterson and Campbell's work at critical electrical conditions.

Since oxygen is the only active gas common to all mixtures and since the igniting current is the same in so

* Roy. Soc. Proc. A. vol. xc. pp. 284-285 (1914).

+ Roy. Suc. Proc. A. vol. xcii. pp. 381-401 (1916).

$\ddagger$ Roy. Soe. Proc. A. vol. xei. pp. 17-22 (1914). 
many and varied cases, the suggestion is again strong that ignition begins by some action from the hot wire that is dominated by oxygen. The probability is rather against the emission of positive oxygen ions at low temperatures since oxygen is electronegative. Hydrogen is so intimately related to platinum by the phenomena of absorption that its sensitiveness to iguition by platinum wires can be readily understood on the assumption that the low temperature emission is of hydrogen ions.

The action of methane on hot wires is unknown, except that in certain gas-detectors in which a heated platinum wire forms one arm of a resistance bridge, a cooling effect is observed when the wire is placed in weak mixtures of methane and air. This requires further investigation, but in the present work it has been observed frequently that wires of all metals glow more brightly at the same current in air than in an inflammable mixture. It is highly probabie that any double layer or surface charge would be removed by the flame.

\section{Influence of Gas Pressure.}

(1) Belou Atmospheric.

A further illustration of the indifference of ignition to external physical conditions is given by reducing the pressure of the mixture. The curves of fig. 8 are practically

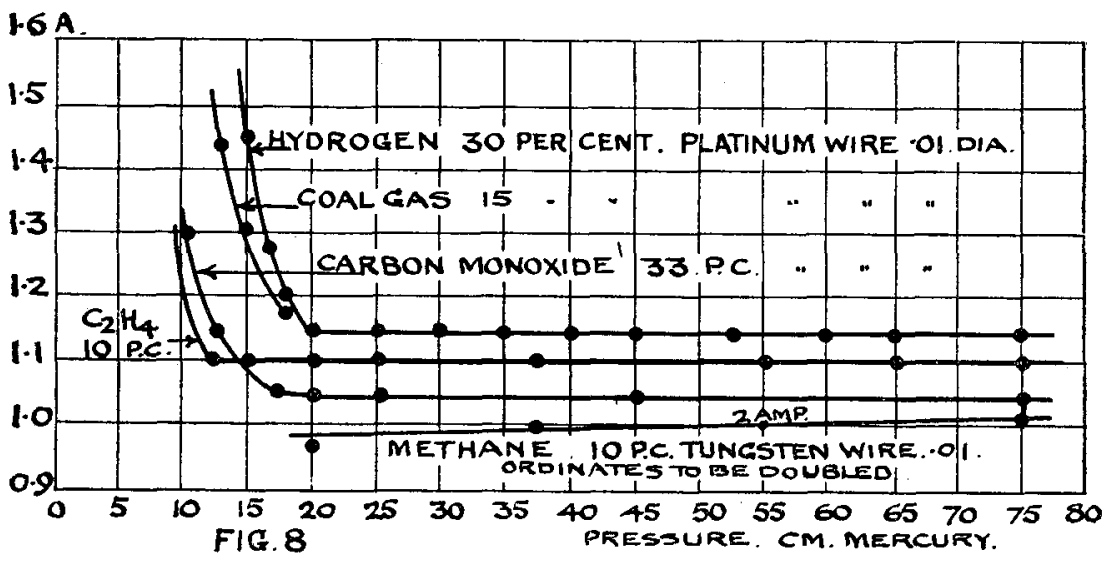

identical; the pressure at which ignition begins to fail is between 12.5 and 20 centimetres of mercury, and below $10 \mathrm{~cm}$. it was impossible. From this point to atmospheric pressure there is no variation of igniting current. 
The rates of absorption and adsorption of gases by metals both vary with pressure, the former as the square root, the latter as the cube root, and it might be expected that any effect depending upon either would vary with pressure, unless the rate of thermionic emission of gases once absorbed wers independent of it.

One property of a gas that is independent of prossure is its viscosity, and on Lodge and Clark's view of the origin of the dust-free space around wires which are strongly illuminated ${ }^{*}$ it is at least possible that heat removed by convection should be controlled by viscosity. On the other hand, gases of such widely differing molecular properties as hydrogen, ethylene, and carbon monoxide have the same. igniting currents.

\section{(2) Above Atmospheric.}

For the higher pressures glass apparatus was replaced by the construction of fig. 9. A wrought-iron tube $\frac{3}{4}$ inch bore and 18 inches long, had at the upper end a cross-piece fitted with a sparking-plug to which the wire was soldered, a quartz window through which it could be observed, and an attachment for a pressure-gauge and gas connexions. At the lower end a T-piece had two ordinary water-taps fitted, one, $B$, joined directly to the water main, the other, $A$, to drain the pipe. At the start the three-way tap $C$ is opened to the atmosphere, A opened to drain the tube. The latter is then closed and B opened, sweeping air or products of combustion through $\mathrm{C}$. The appearance of water here indicates that the tube is full. $B$ is then closed and $C$ turned to the gas supply, A opened and a measured quantily of water drawn off, corresponding to the pressure required, the object being to have at least 30 cubic centimetres of gas to explode. $\mathrm{A}$ is then closed and B opened, admitting water and compressing the gas. 'The pressure could be readily controlled up to 100 pounds to the square inch, the highest pressure of the mains.

Explosions are heard as a faint click or can be seen through the window. The cock on the gauge must be closed before explosion.

The results with hydrogen and coal gas, the only gases to be had at the time in large volumes, using platinum wire, were as follows (Table V.).

* "On the Phenomena exhibited by Justy Air in the neighbourloood of strongly Illuminated Bodies," O. J. Lodge and J. W. Clark. Phil. Mag. March 1884, p. 214.

Phil. Mag. S. 6. Vol. 38. No. 227. Nov. 1919. 2 X 
TABLE V.

\begin{tabular}{|c|c|c|}
\hline $\begin{array}{l}\text { Pressures above } \\
\text { atmosphere. }\end{array}$ & $\begin{array}{c}\text { Hydrogen } \\
30 \text { per cent. }\end{array}$ & $\begin{array}{l}\text { Coal Gas } \\
15 \text { per cent. }\end{array}$ \\
\hline 0 lb. per sq. inch, & 5.45 amperes. & $6 \cdot 35$ \\
\hline 20 & $5 \cdot 50$ & 6.40 \\
\hline 40 & $5 \cdot 50$ & $6 \cdot 40$ \\
\hline 60 & $5 \cdot 60$ & 645 \\
\hline 80 & $5 \cdot 80$ & $6 \cdot 50$ \\
\hline 100 & 60 & $7 \cdot 0$ \\
\hline
\end{tabular}

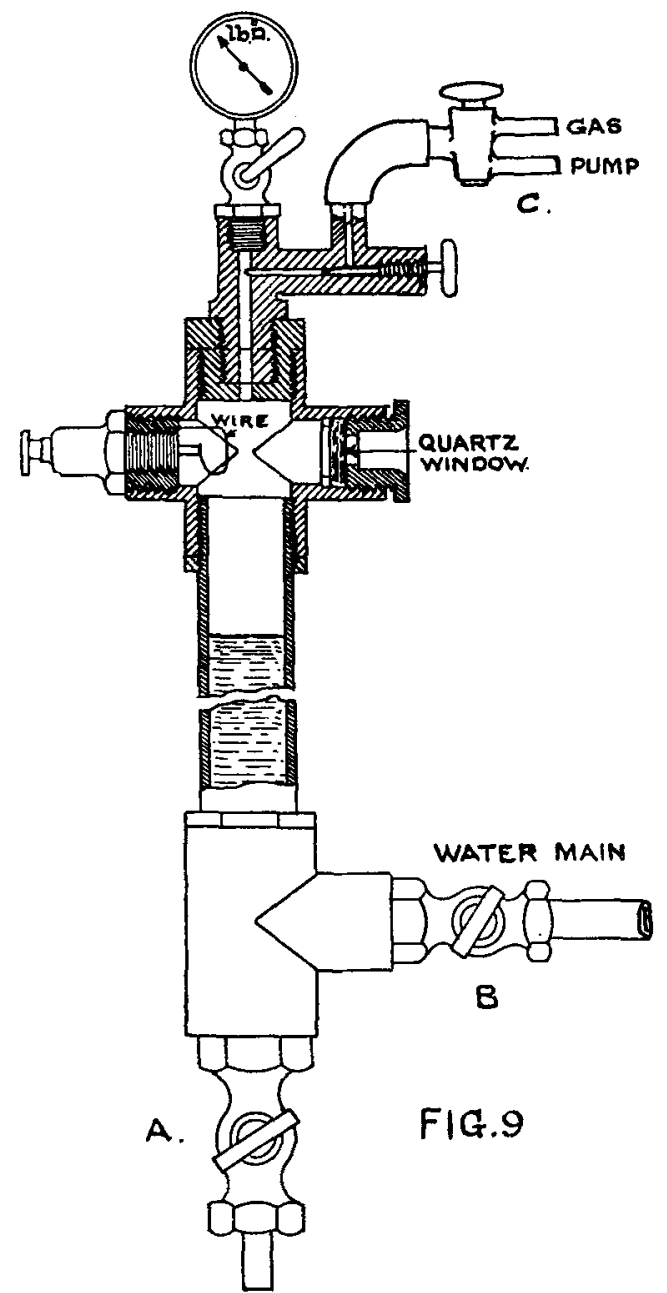

The slight rise is no doubt owing to the cooling effect of the more rapid gas bombardment at higher pressures. When 
the pressure is raised tol several hundred atmospheres it is impossible to ignite the gas by any current short of fusion of the wire *.

We have then the remarkable result that from pressures of 20 to 600 centimetres of mercury the same current causes ignition. This again points to ignition being a trigger effect.

\section{Absence of Infuence of Electric or Magnetic Fields on Hot Wire Ignition.}

The connexions for obtaining a high-tension alternating electrostatic field are shown in fig. 1. A quartz tube with sealed end is threaded through the wire loop. A metal rod fitting inside the tube is one electrode, the other is the ignition wire. Sparks cannot pass but a field high onough to produce "corona" or anything short of it is obtained. When the wire is lueated to redness by the passage of a current from cells switching on the high-tension voltage cools it instantly to blackness. This is caused by the movement of the air ionized by the strong electrustatic field, repelled from and drawn back to the wire with a fanning action sufficient to cool it out. The glow reappears on the approach of a strong magnet. Moving ions are then swept away as soon as formed and the alternating field has no grip upon unelectrified molecules of gas around the wire.

Differences of one per cent. in the brightness of a wire can be measured. To this degree of sensitiveness the change of brightness is a means of indjeating the presence of ions in the gas around it by their fanning action. When the electric field around the wire is unidirectional and insufficient to cause ionization by collision, an alternating magnetic field might by its action on the thermionic discharge have made the latter visible. None could be observed, though the field strength was pushed to a high value. Placing the wire in a tube through which a stream of methane and air was passed, no effect on surface combustion of a steady field of 30,000 lines per sq. $\mathrm{cm}$. could be observed. This again points to an extraordinarily intimate relation between the metal and the burning gas.

\section{Application of Results.}

Apart from the question of endurance or mode of application, it is possible by the use of filaments of metals such

* "Gaseous Combustion at High Pressures," W. A. Bone aud others. Phil. Trans. Roy. Soc. Series A, vol. ccxv. p. 281. 
as nickel, or alloys having a melting-point of the same order, to make electric lamps for use in coal mines which when broken in an inflammable atmosphere of methane and air will not ignite the gas. The resistance of such lamps would be less than carbon or tungsten lamps and this would necessitate some change in the lighting voltage, but combined with an alternating current supply, which makes ignition still more difficult in case of a filament breaking, safety can be assured. Nor would a jartial break, of the tip of the lamp for example, which admitted a slow stream of gas be any more dangerous, for it lias been shown above that hotwire ignition is independent of gas pressure.

To apply this to places, on board ship for example, where. gases such as hydrogen or petrol rapour have to be guarded against, would not be so easy, for in these cases surface combustion begins at temperatures below incandescence, and it is. probable that sound mechanical protection will be preferred both in mines and battery rooms to dependence upon the use of such safety-lamps alone.

\section{Summary.}

Ignition by hot wires occurs at a definite rate of generation of heat in unit Jength which in a steady state at low temperatures is removed by convection and is nearly independent of diameter. Ignition is independent of gas pressure, of the heat of combustion of the mixture, of the proportion of gas present, and for any given metal independent of the nature of the combustible molecule so far as it is affected by change of diameter ; hydrogen and platinum are exceptions. That is, since previous heating of the gas does not affect ignition temperatures, it is on the whole independent of every external physical or chemical variable.

The source of ignition must therefore be sought in some phenomenon depending strictly upon the rate of generation of heat by the passage of the current, but occurring if not within the surface layer of the metal itself so near to it that the ordinary gas laws do not come into action. Oxygen is the only active common component of all the mixtures, and by a process of elimination it can be inferred that the mechanism of hot-wire ignition is an attack upon oxygen either within the wire or by positive ions of combustible gas just ejected from it, for the temperatures at which surface action begins are lower than those which start combination of gases separately heated to a point at which they explode 
on mixture, Electric and magnetic fields have no influence on surface combustion that can be observed by the phenomena of ignition.

Compared with the varied phenomena of spark ignition hot wire ignition is singularly constant in type. A further examination of the electrical and thermal phenomena of surface combustion is to be desired.

LXI. The Fundamental Law for the true photographic rendering of Contrast. By F. F. Revwick, A.C.G.I., F.I.C. ${ }^{*}$

QINCE the publication in May 1890 of their first paper in $O$ the Journal of the Society of Chemical Industry, the views of Hurter and Driffield concerning the scientific principles which should guide photographers in the making of negatives and positives, have been the target for much criticism and the focus of many controversies.

In a paper by Prot. A. W. Porter, F.R.S., and Dr. R. E. Slade in the July issue of the Philosophical Magazine (vol. xxxviii. p. 187, July 1919) there appears a review of the fundamental principles of picture-making which claims to present the whole subject in a new and truer aspect and attributes to Hurter and Driffield "as the result of a somewhat quick judgment" ... "an imperfect conception of the true conditions for securing a true representation of gradation."

It appears to the present writer unfortunate that at the time they wrote their paper Porter and Slade were unacquainted with both Lord Rayleigh's paper (Phil. Mag. xxii. p. 734 (1911), reprinted Brit. Journ. Phot. lviii. p. 994 (1911) ) and with the 1916 Traill Taylor Memorial lectu'e before the Royal Photographic Society (Phot. Journ. vol. lvi. p. $222(916)$ ) to which they refer in their last two paragraphs, or they would doubtless have dealt less fully with some points which have long since received general acceptance and more fully with others on which they seem to hold different views from most of those who have worked at photographic science during the last decade or two.

I propose later to describe my method of deducing the "reciprocal" curves employed in the 1916 Traill Taylor lecture, and to show that it has a more general applicability

* Communicated by the Author. 